\title{
Erratum to: A piecewise linear modeling approach for testing competing theories of habitat selection: an example with mule deer in northern winter ranges
}

Jeffrey A. Manning • Edward O. Garton

Published online: 14 February 2013

(c) Springer-Verlag Berlin Heidelberg 2013

\section{Erratum to: Oecologia}

DOI 10.1007/s00442-012-2532-4

Unfortunately, in the original version of article, Eq. 4 and Fig. 2 were wrongly published. The corrected equation is given below and the figure is reproduced in the following page.

$Y_{i}=\beta_{o}+\beta_{1} X_{1}+\beta_{2} X_{E_{I}}+\beta_{3} X_{E_{I}}+\beta_{4} X_{E_{H}}+\beta_{5} X_{1} X_{E_{H}}+\eta_{i}$ 


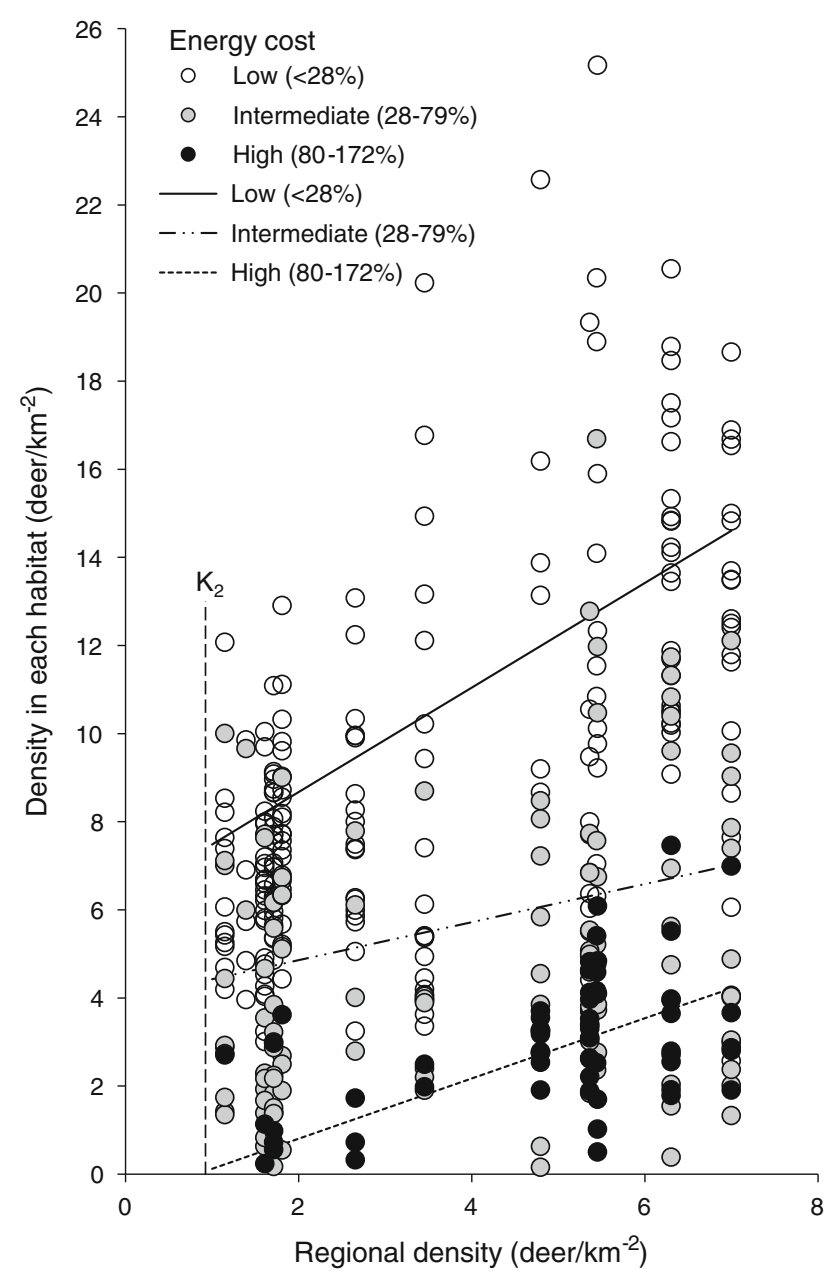

Fig. 2 Density of mule deer (Odocoileus hemionus) in three winter range habitats as a function of regional population density in five game management units (regions) of western Idaho, USA, predicted by the ideal free distribution model $\left(w_{i}=0.94\right.$, pseudo $R^{2}=0.64$; see Eq. 3 in Materials and methods). Habitat classification was based on net energy costs, identified using the energy cost model of Parker et al. (1984), as modified by Manning and Garton (2012). $K_{2}$ marks where colonization in the high- and intermediate-quality habitats is dampened when colonization of low-quality habitat begins 